\title{
Influence of Compaction Pressure and Particle Content on Thermal and Mechanical Behavior of Artificial Marbles with Marble Waste and Unsaturated Polyester
}

\author{
Carlos Eduardo Gomes Ribeiro ${ }^{a, b *}$, Rubén Jesus Sánchez Rodriguez $z^{a}$ \\ ${ }^{a}$ Laboratory of Advanced Materials, Polymer and Composites Section, Universidade Estadual do Norte \\ Fluminense Darcy Ribeiro - UENF, Av. Alberto Lamego, 2000, Campos dos Goytacazes, RJ, Brazil \\ ${ }^{b}$ Mechanical Engineering Section, Instituto Federal do Espirito Santo - IFES, Campus Cachoeiro de \\ Itapemirim, Rodovia Cachoeiro x Alegre, Km 5, Morro Grande, Cachoeiro de Itapemirim, ES, Brazil
}

Received: December 15, 2014; Revised: October 20, 2015

\begin{abstract}
Compact artificial stones are widely used in buildings around the world, and the expected demand to the next years is increasing. In this study, stone fragments from marble processing are recycled as raw materials for produce compact artificial stones using compaction in a vacuum environment $(100 \mathrm{~mm} \mathrm{Hg})$. Crushed marble waste $(80$ and $85 \% \mathrm{wt})$ are mixed with unsaturated polyester resin as binder. Materials were processed under compaction pressures of 1 and $10 \mathrm{MPa}$, for 20 minutes at $90{ }^{\circ} \mathrm{C}$. Artificial marble with flexural ultimate strength of $25 \mathrm{MPa}$, water absorption below $0.2 \%$ and homogeneous particles distribution were obtained to materials produced with $80 \%$ wt of marble particles. To artificial marbles with $85 \%$ wt of particles, lower flexural ultimate strength and higher water absorption were observed ( $18 \mathrm{MPa}$ and $0.4 \%$ respectively). In addition, the greater compaction pressure used improves slightly values obtained in 3 points bending test. Furthermore, tangent delta peaks at $115^{\circ} \mathrm{C}$ were observed to evaluated artificial marbles.
\end{abstract}

Keywords: artificial stone, vacuum compaction, marble waste

\section{Introduction}

Artificial stones, often known as engineered stones or compound stones, have shown a high market value and an ever-growing demand in the past few years ${ }^{1}$. Brazil has imported approximately 60 thousand tons of artificial stone in 2014. It is believed that the international market for this material will experience some growth over the next few years, with an expected demand of 251 million square feet for the US market in 2016, which is $36 \%$ larger than for $2011^{2}$.

These materials are composed of up to $94 \%$ natural aggregates. These aggregates may be composed of marble particles, granite particles, quartz sand or glass crystals such as silicon or silicon oxide. Artificial stones represent an excellent option for the recycling of post-process residue by the natural stone industry3.

Artificial stones are acknowledged by their good mechanical performance and homogeneity, although very few studies on their behavior have been published in the literature.

Lee et al. ${ }^{4}$ evaluated the effects of compaction pressure, vacuum level and vibration frequency in physical and mechanical properties of artificial stones, pointing that higher compaction pressures improves mechanical properties up to the level which compaction pressure promotes the breakdown of the particles. Lee and coworkers use granite and glass particles, furthermore $8 \% \mathrm{wt}$ of unsaturated polyester, thus, artificial stones made with marble particles and higher contents of unsaturated polyester can present different behavior than artificial stones produced by Lee.

*e-mail: carlospcp@hotmail.com
Borsellino et al..$^{5}$ evaluated effect of marble particle contents on mechanical and chemical resistance of artificial stones. Authors point that higher particle contents promotes lower flexural ultimate strength, however, authors not use vacuum in artificial marbles production, obtaining big voids. Effects of compaction pressure were not evaluated.

Previous studies ${ }^{6-8}$ reported mechanical behavior of artificial stones produced with marble particles in $85 \% \mathrm{wt}$ and unsaturated polyester, pointing to high mechanical resistance materials. Changes in composition or compaction pressure were not evaluated

In addition, unpublished discussion about thermogravimetric behavior of artificial stones and dynamical mechanical analysis are present as part of characterization and deep analysis of composition and pressure effects

This research aims to study compaction pressure and composition effects on physical indexes, microstructure, mechanical resistance and thermal behavior of artificial marbles (AM) produced with marble waste. It represents a new environmentally friendly product that uses waste to produce high-value products.

\section{Material and Methods}

\subsection{Marble waste}

The waste of "Calcita" natural marble (NM), from Polita company, in Cachoeiro de Itapemirim, ES, Brazil, was used in this study. Fragments of marble blocks were collected at the end of the sawing of block. After the material collection, the 
residue was crushed using a jaw crusher, such that particles could pass through a $2 \mathrm{~mm}$ sieve.

\subsection{Unsaturated polyester}

Orthophthalic unsaturated polyester (UPR) resin was used to formulate all artificial marbles. As initiator $1 \mathrm{wt} \%$ of a methyl ethyl ketone peroxide (MEKP) was used.

\subsection{Fabrication of slabs from residue}

For determine mechanical and physical properties, besides thermal behavior, four material specimens were casted (Table 1).

The granulometric composition of marble particles was based in simplex mixture design presented in other studies ${ }^{8,9}$.

Particles, that were previously crushed and classified, were dried, weighed and putted in a vacuum planetary mixer. Dry particles are a necessary step because water may reduce the cure process efficiency related to adhesion between the composite components ${ }^{10}$. The unsaturated polyester was introduced into the mixer by vacuum suction. After marble waste and resin mixed for 2 minutes, the mass was vacuum transferred to mold $(100 \times 100 \mathrm{~mm})$, the mold was vibrated for 2 minutes to spread the mass. After vibration, the mold was uncoupled from mixer and hot vacuum pressed for 20 minutes at $90^{\circ} \mathrm{C}$.

\subsection{Chemical and mineralogical composition of marble waste}

Quantitative mineralogical composition of the marble waste was obtained by means of X-ray diffraction (XRD) performed on powdered samples. XRD analysis was performed using a SHIMADZU XDR-7000 diffractometer operating using Copper $\mathrm{K} \alpha$ radiation and $2 \theta$ ranging from $3^{\circ}$ to $90^{\circ}$. Chemical composition was determined by X-ray fluorescence using a Panalytical Axios Max spectrometer (elements are presented in oxide form).

\subsection{Density, water absorption and apparent porosity}

The density, water absorption and apparent porosity from both pure and artificial marble were determined by the ABNT NBR $15845^{[11]}$ standard. Twelve cubic specimens with lattices of approximately $30 \mathrm{~mm}$ in length were evaluated to each material.

\subsection{Artificial marble composition}

Thermogravimetric analysis (TGA) was performed on raw materials and artificial marbles to characterize the thermal behavior and composition of artificial marble.

Table 1. Compaction pressure and composition of evaluated artificial marbles.

\begin{tabular}{ccc}
\hline Material & $\begin{array}{c}\text { Compaction } \\
\text { pressure } \\
\text { (MPa) }\end{array}$ & $\begin{array}{c}\text { Composition } \\
\text { (\%wt of UPR) }\end{array}$ \\
\hline AM1 & 1 & 15 \\
AM2 & 1 & 20 \\
AM3 & 10 & 15 \\
AM4 & 10 & 20 \\
\hline
\end{tabular}

A TA Instruments SDT 2960 thermal analyzer was used set to a nitrogen atmosphere $(100 \mathrm{~mL} / \mathrm{min})$ with a $10{ }^{\circ} \mathrm{C} / \mathrm{min}$ heating rate, using platinum pans and a temperature range from 25 to $950{ }^{\circ} \mathrm{C}$.

\subsection{Flexural ultimate strength and elastic modulus}

Flexural tests were performed using the EMIC DL 10000 Universal Testing Machine. Twelve samples to each material were tested in three point bending test. The test specimens were with dimensions $100 \times 25 \times 10 \mathrm{~mm}$ and were tested at $0.25 \mathrm{MPa} / \mathrm{s}$.

Ultimate Strength (SUT) and Elastic Modulus (E) for the raw materials and artificial marbles were presented as means \pm standard error.

\subsection{Dynamic mechanic behavior}

Dynamic mechanical analysis was performed to improve the understanding of the mechanical properties previously determined at the molecular level. The analysis was performed using a TA Instruments Q800 dynamic mechanical analyzer operating at $1 \mathrm{~Hz}$ and $3{ }^{\circ} \mathrm{C} / \mathrm{min}$. Specimens were fixed using a dual cantilever clamp and the temperature was increased from 0 to $170^{\circ} \mathrm{C}$. Specimen dimensions were $35 \times 12 \times 6 \mathrm{~mm}$.

\subsection{Microstructure}

The polished cross section of produced artificial marbles, were analyzed by scanning electron microscopy (SEM) in a JSM 6460 LV JEOL equipment, at $20 \mathrm{Kv}$. The polished samples were observed with backscattered electrons, without gold deposition.

\section{Results and Discussion}

\subsection{Chemical and Mineralogical Composition of marble waste}

The "Calcita" marble waste is predominantly composed of calcite $\left(\mathrm{CaCO}_{3}\right)$ as shown by the X-ray diffractogram (Figure 1).

Other minerals, such as dolomite $\left(\mathrm{CaCO}_{3} \mathrm{MgCO}_{3}\right)$, diopside $\left(\mathrm{CaMgSi}_{2} \mathrm{O}_{6}\right)$, quartz $\left(\mathrm{SiO}_{2}\right)$, and actinolite $\left((\mathrm{Ca}, \mathrm{Na})_{2}(\mathrm{Mg}, \mathrm{Fe})_{5}(\mathrm{Si}, \mathrm{Al})_{8} \mathrm{O}_{22}(\mathrm{OH})_{2}\right)$, composed of elements found in small amounts by chemical analysis, exhibit lowintensity diffraction peaks.

\subsection{Density, water absorption and apparent porosity}

Table 2 presents average values of density, water absorption and apparent porosity. Figure 2 shows mean \pm standard error to density and water absorption of artificial marbles (AMs).

From the density average values displayed in Table 2 and Figure 2, we observe that use of higher compaction pressure promotes higher densities to AMs, pointing to a greater packing of marble particles. In addition, AMs with different unsaturated polyester contents, show biggest differences in density values, caused by difference in densities between binder and particulate phase.

For water absorption and apparent porosity, compaction pressure not presents significative effect in properties value, 
while a greater content of UPR promotes lower porosities and water absorptions, associated to the lower porosity presented by UPR phase.

Lee et al. ${ }^{4}$ presents artificial stones produced with several variable combinations. Authors report that higher compaction pressures promote higher densities and lower water absorptions, associated to better particle packing. To artificial stones produced with $9.8 \mathrm{MPa}$ of compaction pressure, $50 \mathrm{~mm} \mathrm{Hg}$ of vacuum level and $8 \% \mathrm{wt}$ of unsaturated polyester, authors present density of $2.11 \mathrm{~g} / \mathrm{cm}^{3}$, and water absorption of $0.20 \%$. With greater particle content than AMs, greater density was expected for Lee's material, however, with increasing the particle concentration, the viscosity is higher, because the powder presence reduces the flow capability, as a consequence, the workability of the system is lower, and lower packing of particles is obtained for the same compaction pressure. In addition, according with observed in Table 2, a greater content of particles is associated

Table 2. Physical indexes from raw materials and produced artificial marbles (means \pm standard error).

\begin{tabular}{cccc}
\hline Material & $\begin{array}{c}\text { Density } \\
\mathbf{( g / \mathbf { c m } ^ { 3 } )}\end{array}$ & Water absorption (\%) & Apparent porosity (\%) \\
\hline UPR & $1.23 \pm 0.00$ & $0.07 \pm 0.02$ & $0.08 \pm 0.02$ \\
NM & $2.79 \pm 0.02$ & $0.11 \pm 0.01$ & $0.32 \pm 0.02$ \\
AM1 & $2.26 \pm 0.00$ & $0.17 \pm 0.01$ & $0.39 \pm 0.02$ \\
AM2 & $2.35 \pm 0.00$ & $0.39 \pm 0.04$ & $0.93 \pm 0.10$ \\
AM3 & $2.27 \pm 0.01$ & $0.18 \pm 0.03$ & $0.42 \pm 0.07$ \\
AM4 & $2.37 \pm 0.00$ & $0.42 \pm 0.05$ & $0.98 \pm 0.11$ \\
\hline
\end{tabular}

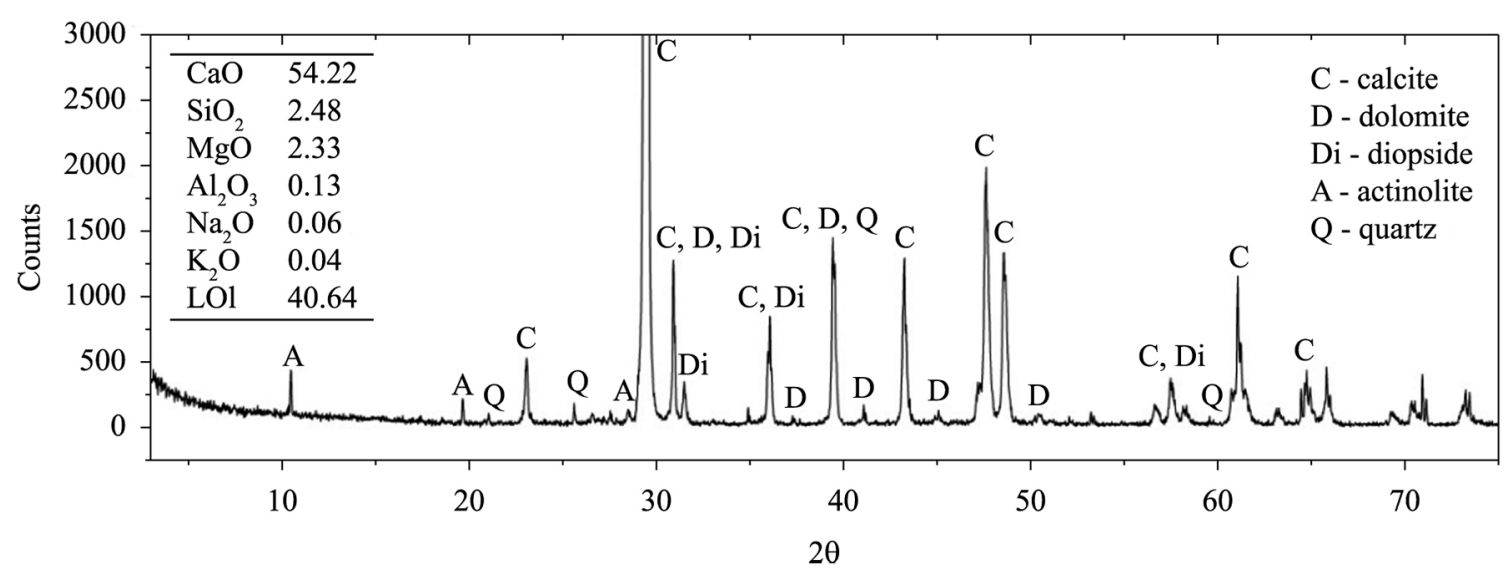

Figure 1. X-ray diffraction pattern and chemical composition (wt $\%)$ of the marble waste sample.

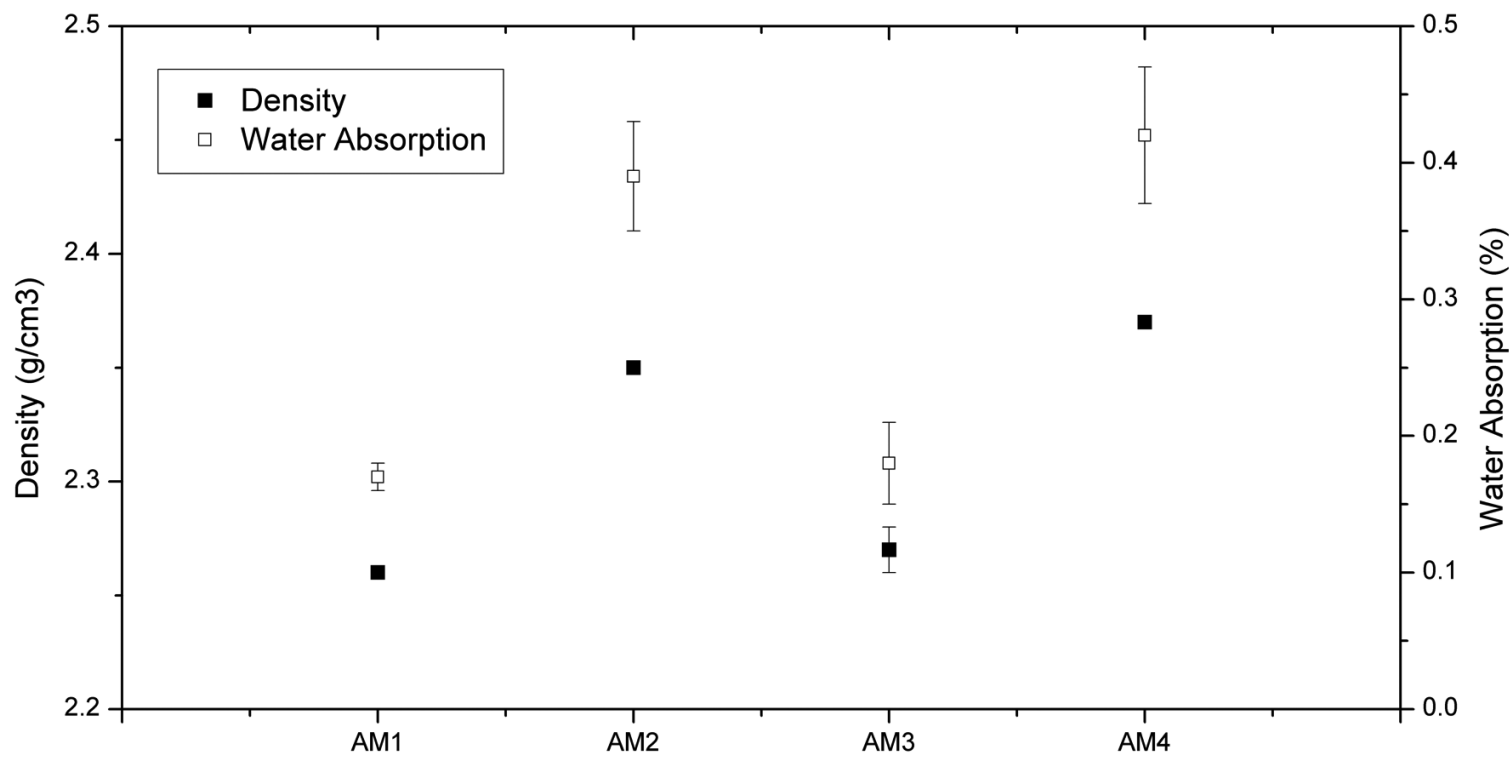

Figure 2. Average values for density and water absorption of produced artificial marbles (AM1, AM2, AM3, AM4). Mean + standard error. 
with higher water absorptions, however, the lower porosity presented by silicious particles used by Lee and coworkers, when compared with marble particles, promoted lower water absorption for artificial stone produced by them.

Lam dos Santos et al. ${ }^{12}$ presents a study with three commercial artificial stones. Materials evaluated by authors were produced with silicious particles. The authors reported densities between 2.36 and $2.42 \mathrm{~g} / \mathrm{cm}^{3}$, compatible with values found for AMs produced with $85 \%$ wt of NM. Although similar densities, the porosities related by Lam dos Santos were significantly lower $(<0.05 \%)$, associated with greater water absorption presented by NM particles when compared with silicious aggregates.

In previous work ${ }^{8}$ were evaluated artificial marbles produced with calcitic particles and $15 \%$ wt of unsaturated polyester. In addition, were used compaction pressure of $10 \mathrm{MPa}$ and $100 \mathrm{~mm} \mathrm{Hg}$ as vacuum level. For all evaluated compositions were obtained $2.36 \mathrm{~g} / \mathrm{cm}^{3}$ for density, the same value observed for AM2 and AM4, produced with same UPR content. Despite the same density value, observed water absorptions were around $0.20 \%$, half than observed to materials produced with the same UPR content, associated to a different procedure used in property determination.

In others previous works ${ }^{6,7}$ were evaluated artificial marbles produced with dolomitic particles and $15 \%$ wt of unsaturated polyester. Were obtained $2.27 \mathrm{~g} / \mathrm{cm}^{3}$ for densities, in addition, 3.64 and $0.67 \%$ for water absorptions. The lowest densities and high water absorptions are attributed to high porosity content of presented materials. In the first case (3.64\% of water absorption) a high porosity is promoted by a non-reactive solvent addition, that when comes out of material leave voids. In the second case $(0.67 \%$ of water absorption), air bubbles imprisoned during mass transfer from mixer for mold, promotes the high porosity value.

\subsection{Artificial marble composition}

Figure 3 shows that the natural marble exhibited a $44 \%$ mass loss at approximately $850{ }^{\circ} \mathrm{C}$, corresponding to the decomposition of calcium carbonates. Furthermore, above $600{ }^{\circ} \mathrm{C}$, all unsaturated polyester mass was consumed.

The behavior observed to marble waste is according with related by other authors to calcite. Souza and Bragança ${ }^{13}$ reports that calcination of calcite with $57 \%$ wt of $\mathrm{CaO}$ ends around $850{ }^{\circ} \mathrm{C}$ and promote a weight loss of $43 \%$. Barcina et al. ${ }^{14}$ reports a weight loss of $44 \% \mathrm{wt}$, that occurs around $800{ }^{\circ} \mathrm{C}$, for a limestone analyzed.

Concerning the orthophthalic unsaturated polyester the same behavior is observed in Kandare et al. ${ }^{15}$ when authors evaluating an orthophthalic unsaturated polyester by thermogravimetric analisys. Kandare and coworkers attributed the three stages of polyester decomposition as (i) loss of water via dehydratation, (ii) rupture of polyester and polystyrene chains, and (iii) a char oxidation stage. The mass losses and temperature ranges presented in Figure 3 for the three stages are the same related by Kandare.

By analyzing the artificial marbles curves, it is found a mass reduction of approximately $12.5 \%$ for materials with predicted polyester content of 15\% (AM2 and AM4) and mass reduction around $20 \%$ for materials with predicted polyester content of $20 \%$ (AM1 and AM3) occurred slightly above $600{ }^{\circ} \mathrm{C}$, corresponding to the mass fraction of the unsaturated polyester.

A second mass reduction was observed between 650 and $850{ }^{\circ} \mathrm{C}$, corresponding to $44 \%$ of the remaining mass, and is associated with the $\mathrm{CaCO}_{3}$ decomposition into oxides.

\subsection{Flexural ultimate strength and elastic modulus}

The average values for Flexural Ultimate Strength $\left(\mathrm{S}_{\mathrm{UT}}\right)$ and Flexural Elastic Modulus (E) are presented in Figure 4 and Table 3 .

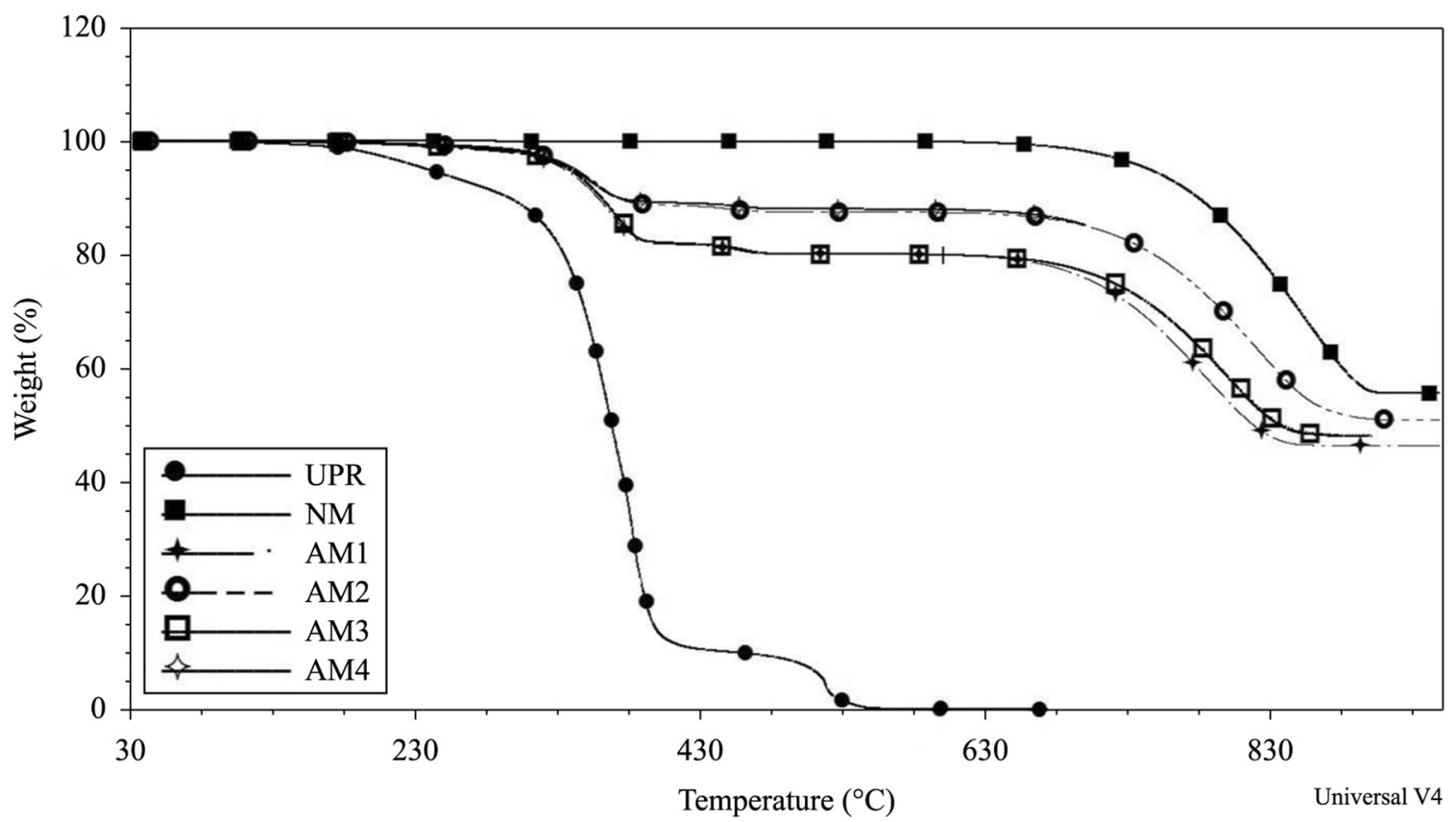

Figure 3. Thermogram for natural marble (NM), unsaturated polyester (UPR) and artificial marbles (AM1, AM2, AM3 and AM4). 


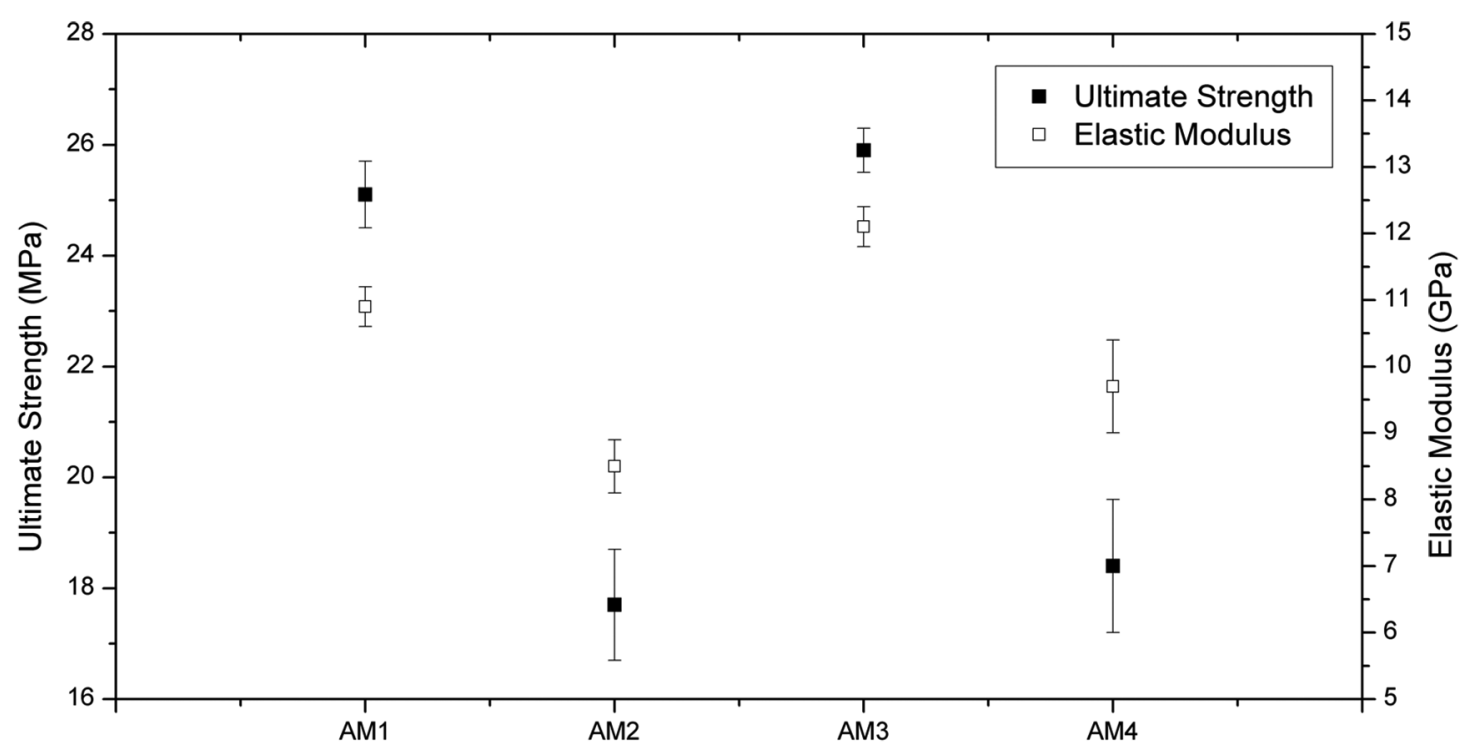

Figure 4. Ultimate strength $\left(\mathrm{S}_{\mathrm{UT}}\right)$ and Elastic Modulus (E) of produced artificial marbles (AM1, AM2, AM3, AM4). Mean + standard error.

Table 3. Flexural properties of raw materials and produced artificial marbles (means \pm standard error).

\begin{tabular}{ccc}
\hline Specimen & $\mathbf{S}_{\mathbf{U T}}(\mathbf{M P a})$ & $\mathbf{E}(\mathbf{G P a})$ \\
\hline NM & $7.0 \pm 0.4$ & $4.9 \pm 0.2$ \\
$\mathbf{U P R}$ & $100.4 \pm 2.5$ & $1.9 \pm 0.0$ \\
AM1 & $25.1 \pm 0.6$ & $10.9 \pm 0.3$ \\
AM2 & $17.7 \pm 1.0$ & $8.5 \pm 0.4$ \\
AM3 & $25.9 \pm 0.4$ & $12.1 \pm 0.3$ \\
AM4 & $18.4 \pm 1.2$ & $9.7 \pm 0.7$ \\
\hline
\end{tabular}

From the average values displayed in Figure 4 and Table 3, we observe that use of higher compaction pressure promotes higher $\mathrm{S}_{\mathrm{UT}}$ and $\mathrm{E}$ to produced artificial marbles (AMs), pointing that a greater packing of marble particles, expressed by higher density values, promotes a little increase in flexural properties.

In addition, AM1 and AM3, with $20 \%$ wt of unsaturated polyester (UPR), presented higher values in flexural test and lower dispersion than AM2 and AM4, produced with $15 \%$ wt of UPR, as consequence of lower porosity and higher mechanical resistance presented by UPR.

From Table 3, flexural elastic modulus obtained for produced AMs are greater than obtained to raw materials. The UPR is well-adhered to the particles and create an interface between marble particles better than grain boundaries of NM. As consequence, E of artificial marbles were around 2 times greater than of NM.

In addition, under flexural loading, the tensile force below the neutral axis not only prevents the closure of microcracks, but also causes them to nucleate and grow. This fact is responsible for the lower stiffness of natural marble during bending. The UPR phase gives the material a decreased tendency to crack formation and growth.

Lee et al. ${ }^{4}$ presented values of 27.9 and $46.6 \mathrm{MPa}$ for $\mathrm{S}_{\mathrm{UT}}$ to artificial stones produced with compaction pressures of 4.9 and $9.8 \mathrm{MPa}$ respectively. According with authors the biggest $\mathrm{S}_{\mathrm{UT}}$ promoted by higher compaction pressure is associated with greater particle packing, as pointed by higher density and lower water absorption. To AMs a similar effect were observed, however, with lower magnitude. Concerning lower $\mathrm{S}_{\mathrm{UT}}$ presented by AMs, when compared with ultimate strengths obtained by Lee and coworkers, it is associated with lower resistance and higher porosity presented by marble particles, when compared with siliceous particles used by Lee, furthermore, authors used vibration during compaction what improves particle packing promoting higher mechanical resistance.

Borsellino et al. ${ }^{5}$ presents $16.6 \mathrm{MPa}$ as $\mathrm{S}_{\mathrm{UT}}$ and $9.1 \mathrm{GPa}$ as $\mathrm{E}$ of artificial marble with $80 \mathrm{wt} \%$ of calcitic marble. Similar values were expected for AMs with $20 \%$ wt of UPR (AM2 and AM4) and lower values were expected for AMs produced with lower UPR content (AM1 and AM3), however, higher flexural resistance were observed to evaluated artificial marbles (Table 3). The big voids observed in Borsellino's artificial marbles promoted lower flexural values.

In previous work ${ }^{6}$ 9.2 Mpa was presented as $\mathrm{S}_{\mathrm{UT}}$ of artificial marble with $15 \%$ wt of UPR, half than observed to artificial marbles produced with same UPR content (AM2 and AM4). Authors report that use of non-reactive solvent promotes a high void content what cause stress concentration and lower mechanical resistance.

In other previous work $\mathrm{k}^{7} 15 \mathrm{Mpa}$ was presented as $\mathrm{S}_{\mathrm{UT}}$ of artificial marble produced with $15 \%$ wt of UPR, slightly smaller than observed to AM2 and AM4, produced with same UPR content. The lower flexural resistance of previous artificial marble is attributed at higher porosity reported by authors.

\subsection{Dynamic mechanic behavior}

Figure 5 show storage modulus and tangent delta from raw materials and produced artificial marbles (AMs).

From storage modulus presented in Figure 5 were observed that AMs storage modulus are greater than UPR storage modulus both in glass state $(\mathrm{T}<\mathrm{Tg})$ as in rubbery state $(\mathrm{T}>\mathrm{Tg})$. 
Kajohnchaiyagual et al. ${ }^{16}$ evaluated effect of high filled polibenzoxazine. It were used between 50 and $83 \%$ wt of alumina particles. Authors report that higher filler content promotes higher storage modulus. In this way, AM2 and AM4 should present higher modulus than AM1 and AM3, as consequence of your high NM content.
Baskaran et al. ${ }^{17}$ also evaluate effect of particle content in polymer filling. Authors report that increase in particle content improves storage modulus up to $20 \% \mathrm{wt}$ of granite particles, furthermore, particle contents higher than $20 \% \mathrm{wt}$ promotes decreasing in storage modulus. Baskaran associate these behavior to agglomerated particle region, like seen

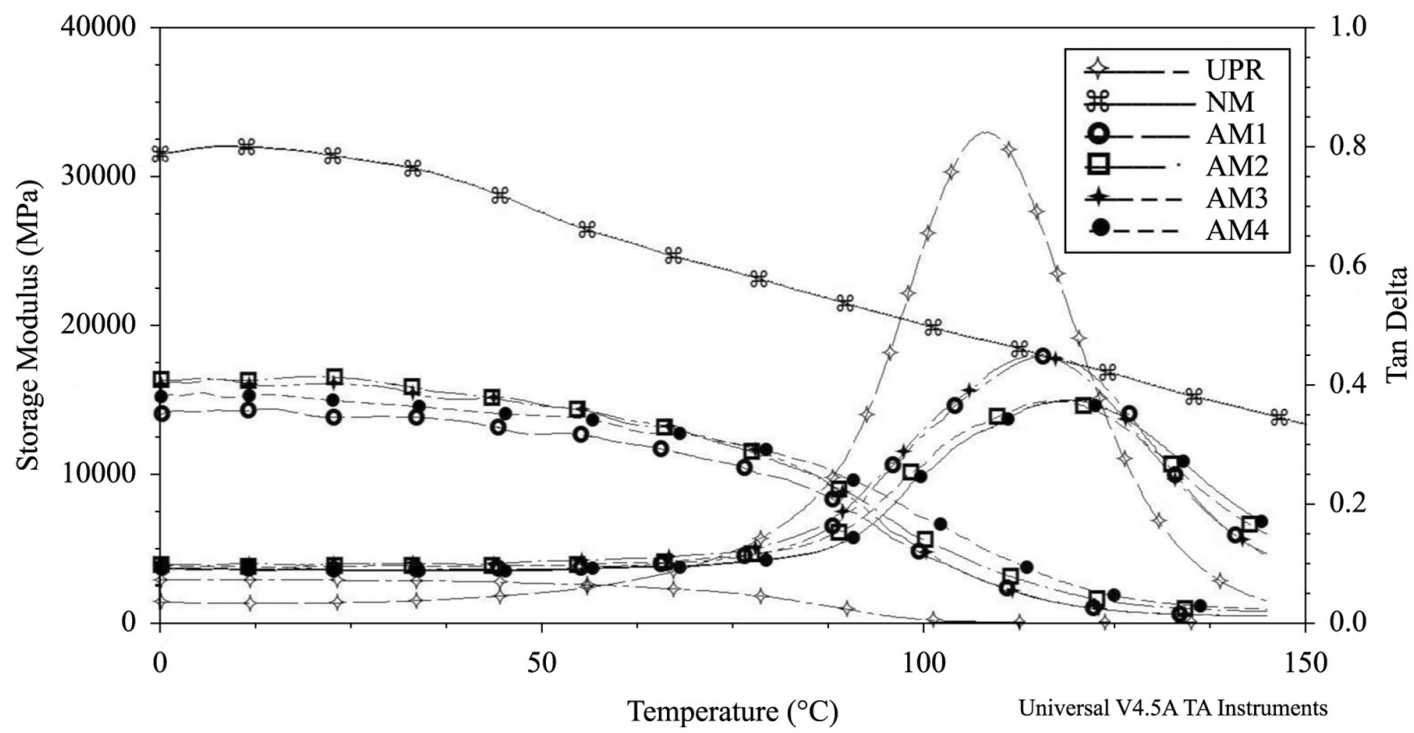

Figure 5. Storage modulus and tangent delta curves for natural marble (NM), unsaturated polyester (UPR), and produced artificial marbles (AM1, AM2, AM3 and AM4).
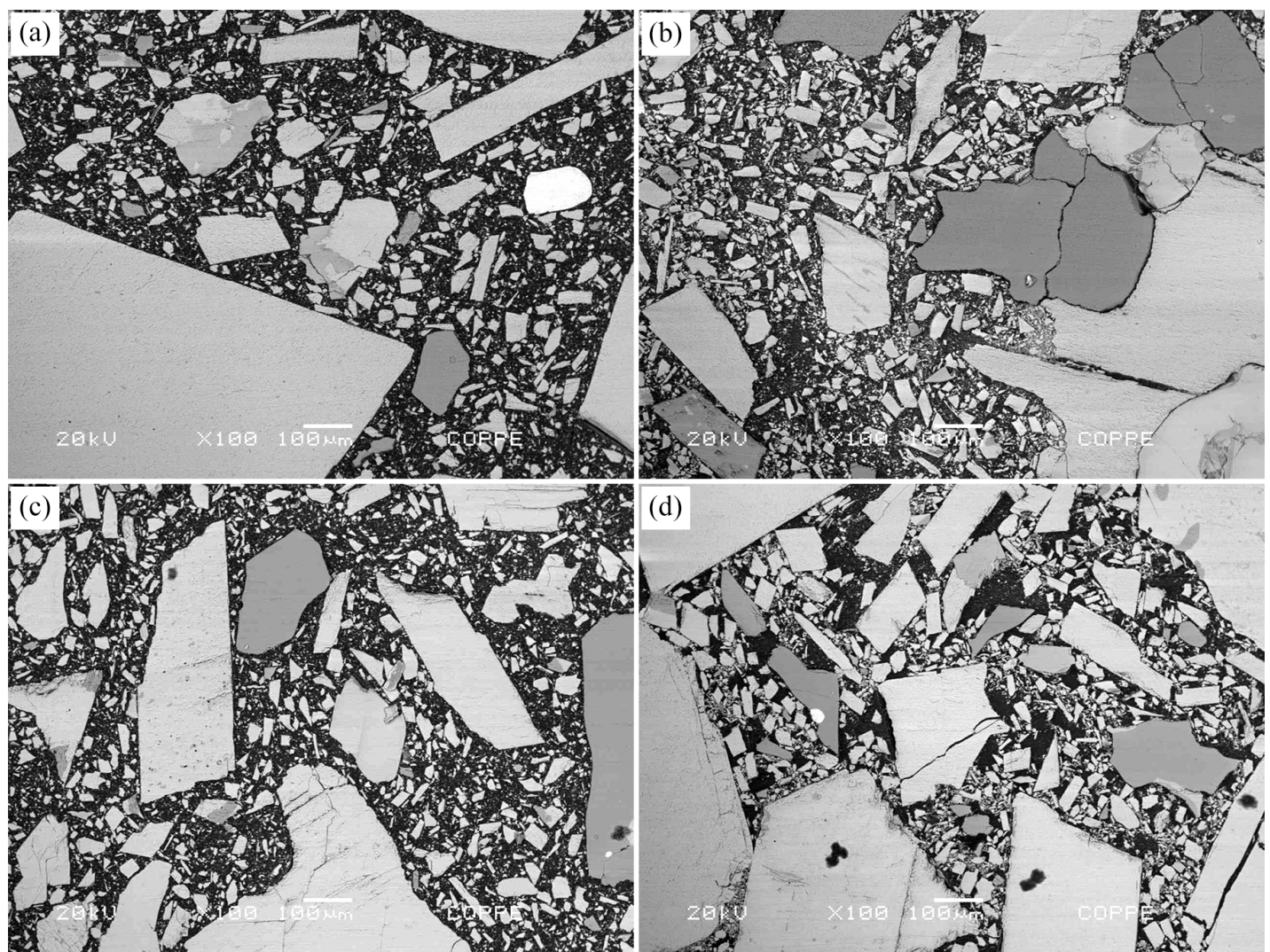

Figure 6. Polished cross section of AM1 (a); AM2 (b); AM3 (c) and AM4 (d). Magnification 100 X. 
in Figure 6 for AM2 and AM4, pointing that lower storage modulus can be associated with structural heterogeneities.

The AMs storage modulus were between of your constituents due to morphology impact. The AMs don't have a continuous marble phase with higher storage modulus and by the other hand the UPR with lower storage modulus present an anchorage effect on chains mobility introduced to marble waste.

The tangent delta curves (Figure 5) of AMs presents Tg about $10^{\circ} \mathrm{C}$ values greater than observed to UPR. To AMs the tangent delta curves behavior don't show big differences in Tg when pressure and composition is changed, affecting mainly the intensity of peaks, associated with damping capacity of material. The AM2 and AM4 show specific composition effect on tan delta intensity, small peaks pointing to greater restriction of conformational movements of polymer chains associated to more efficient interphase interaction (good adhesion) between unsaturated polyester and marble particles ${ }^{16,18,19}$.

All artificial marble compositions presented $\mathrm{Tg}$ values near to $115^{\circ} \mathrm{C}$, pointing that materials are in glass state at ambient temperature.

\subsection{Microstructure}

Figure 6 presents SEM micrographs of polished cross section for AM1(a), AM2(b), AM3(c) and AM4(d).

From Figure 6 was observed that the use of higher compaction pressure $(10 \mathrm{Mpa})$ promotes slightly greater particle package, reflected by higher density values and higher values in flexural test.

Regarding the composition, Figure 6 show like higher particle content is associated to greater particle packing, furthermore, artificial marbles with lower particle content (AM1 and AM3) presents more homogeneous particle distribution.

The heterogeneities in AM2 and AM4 comprise regions with particle agglomeration that locally presents a low unsaturated polyester content, what is associated with higher water absorption and lower mechanical resistance.

\section{References}

1. Abirochas. Balanço das exportações, importações e consumo interno brasileiro de rochas ornamentais em 2014. ABIROCHAS; 2015. Available from: <http://www.abirochas.com.br/noticia. php?eve_id=3397>. Access in: 15 Oct. 2015.

2. Woodworking Network. US Demand for Cast Polymers to Reach 251 Million Sq. Ft. in 2016. Vance Publishing Corporation; 2012. Available from: $<$ http://www.woodworkingnetwork. com/wood-market-trends/woodworking-industry-trends-pressreleases/US-Demand-for-Cast-Polymers-to-Reach-251-MillionSq-Ft-in-2016-149739755.html>. Access in: 15 Oct. 2015.

3. Breton; 2013. Available from: <http://www.breton.it/ engineeredstone/it\#>. Access in: 15 Oct. 2015.

4. Lee MY, Ko CH, Chang FC, Lo SL, Lin JD, Shan MY, et al. Artificial stone slab production using waste glass, stone fragments and vacuum vibratory compaction. Cement and Concrete Composites. 2008; 30(7):583-587. http://dx.doi.org/10.1016/j. cemconcomp.2008.03.004.

\section{Conclusions}

This study produced artificial marble slabs from marble waste, with mechanical resistance greater than presented by natural marble used in your production.

Under compaction pressure of $10 \mathrm{MPa}$, vacuum condition at $100 \mathrm{~mm} \mathrm{Hg}$, we obtained artificial stone slabs with flexural strength exceeding $25 \mathrm{MPa}$ and water absorption below $0.2 \%$. In addition peaks of tangent delta near to $115^{\circ} \mathrm{C}$ and storage modulus around $15 \mathrm{GPa}$ were observed to produced artificial marbles.

The change in compaction pressure of 1 to $10 \mathrm{MPa}$ increase slightly density and mechanical behavior of evaluated artificial marbles.

The difference of composition presented most significant effect on evaluated properties. The artificial marbles with $80 \%$ wt of particles show lower densities (around 5\%), and half of water absorption than presented by artificial marbles with $87.5 \%$ wt of particles.

In addition, the lower particle content also promotes most homogeneous particles distribution, higher flexural ultimate strengths (around 40\%) and higher elastic modulus (around 25\%)

Despite the higher porosity and the lower mechanical resistance, artificial marbles produced with $87.5 \% \mathrm{wt}$ of marble particles show flexural ultimate strength around 2.5 times greater than natural marble, furthermore, presents a greater elastic modulus too.

Concerning thermal behavior, all evaluated artificial marbles presented glass state, over the ambient temperature, pointing be able to use in several everyday applications.

Furthermore, dislocated to high temperatures and with lower intensity, when compared with neat unsaturated polyester, tangent delta peaks point to an effective adhesion between marble particles and unsaturated polyester resin.

\section{Acknowledgements}

The authors thank the use of the SEM microscope by the PEMM from COPPE/UFRJ.

5. Borsellino C, Calabrese L and Di Bella G. Effects of powder concentration and type of resin on the performance of marble composite structures. Construction \& Building Materials. 2009; 23(5):1915-1921. http://dx.doi.org/10.1016/j. conbuildmat.2008.09.005.

6. Ribeiro CEG, Rodriguez RJS, Vieira CMF, Carvalho EA, Cândido VS and Monteiro SN. Fabrication of artificial stone from marble residue by resin transfer molding. Materials Science Forum. 2014; 775-776:336-340.

7. Ribeiro CEG, Rodriguez RJS, Vieira CMF, Carvalho EA, Cândido VS and Monteiro SN. Production of synthetic ornamental marble as a marble waste added polyester composite. Materials Science Forum. 2014; 775-776:341-345.

8. Ribeiro CEG, Rodriguez RJS and Vieira CMF. Production of ornamental compound marble with marble waste and unsaturated polyester. In: Yurko J, Zhang L, Allanore A, Wang C, Spangenberger JS, Kirchain RE, et al., editors. EPD Congress 2014. Hoboken: John Wiley \& Sons; 2014. p. 129-136. 
9. Ribeiro CEG, Rodriguez RJS and Vieira CMF. Determination of apparent dry density for ternary mixture of crushed marble waste. In: Yurko J, Zhang L, Allanore A, Wang C, Spangenberger JS, Kirchain RE, et al., editors. EPD Congress 2014. Hoboken: John Wiley \& Sons; 2014. p. 83-90.

10. Ignácio C, Ferraz V and Oréfice RL. Study of the behavior of polyester concretes containing ionomers as curing agents. Journal of Applied Polymer Science. 2008; 108(4):2682-2690. http://dx.doi.org/10.1002/app.27629.

11. Associação Brasileira de Normas Técnicas - ABNT. NBR 15845: rochas para revestimento: método de ensaio. Rio de Janeiro: ABNT; 2010.

12. Lam dos Santos JPL, Rosa LG and Amaral PM. Temperature effects on mechanical behaviour of engineered stones. Construction \& Building Materials. 2011; 25(1):171-174. http://dx.doi.org/10.1016/j.conbuildmat.2010.06.042.

13. Souza F and Bragança SR. Thermogravimetric analisys of limestones with different contents of $\mathrm{MgO}$ and microstructural characterization in oxy-combustion. Thermochimica Acta. 2013; 561:19-25. http://dx.doi.org/10.1016/j.tca.2013.03.006

14. Barcina LM, Espina A, Suárez M, García JR and Rodríguez J. Characterization of monumental carbonate stones by thermal analysis (TG, DTG and DSC). Thermochimica Acta. 1997; 290(2):181-189. http://dx.doi.org/10.1016/S0040-6031(96)03074-2.

15. Kandare E, Kandola BK, Price D, Nazaré S and Horrocks RA. Study of the thermal decomposition of flame-retarded unsaturated polyester resins by thermogravimetric analysis and Py-GC/MS. Polymer Degradation \& Stability. 2008; 93(11):1996-2006. http://dx.doi.org/10.1016/j.polymdegradstab.2008.03.032.

16. Kajohnchaiyagual J, Jubsilp C, Dueramae I and Rimdusit S. Thermal and mechanical properties enhacement obtained in highly filled alumina-polybenzoxazine composites. Polymer Composites. 2014; 35(11):2269-2279. http://dx.doi.org/10.1002/ pc.22892.

17. Baskaran R, Sarojadevi M and Vijayakumar CT. Utilization of granite powder as filler for vynil ester resin. Malaysian Polymer Journal. 2014; 9(1):39-44.

18. Claro S No. DMA: o que é preciso saber antes da sua utilização (part III). Brazilian Journal of Thermal Analysis. 2014; 3(12):26-29.

19. Padal KTB, Srikiran S and Nagendra PS. Dynamic mechanical and thermal properties of jute nano fibre reinforced polymer composite. In: Proceedings of the 5th International and 26th All India Manufacturing Technology, Design and Research Conference - AIMTDR; 2014; Guwahati. Guwahati: Indian Institute of Technology Guwahati; 2014. p. 1-6. 